\title{
Hipnose em pacientes oncológicos: um estudo psicossomático em pacientes com câncer de próstata
}

\author{
Liảa Fenera Caire- Pontifíàa UnivesidadeCatdíca deSãoPaulo, SãoPaulo, Brasil
}

\begin{abstract}
Resumo
A presente pesquisa tem como objetivo interpretar e compreender 0 impacto das ressignificações vivenciais experienciadas em estado hipnótico por pacientes com câncer de próstata sobre a autopercepção de saúde, crença no tratamento e capacidade de prospectar o futuro. Foram acompanhados 12 sujeitos durante 5 sessões de 1 hora de hipnoterapia escalonadas semanalmente. Os instrumentos consistiram em entrevistas individuais, intervenções hipnóticas e registros das entrevistas. Foi eleita a Técnica de Análise Temática para a seleção de temas a serem analisados. Os discursos emergidos nas entrevistas iniciais apresentaram semelhanças no que concerne às vivencias coexistenciais e os tópicos notáveis analisados foram: Sentimentos e impulsos ao impacto do diagnóstico, Significado do câncer e crença na cura, Autopercepção da melhora do câncer, Retomada da capacidade de prospectar o futuro. A conclusão indicou que $100 \%$ dos pacientes acompanhados referiram melhora na saúde, certeza da cura, retomada do humor e incremento nas estratégias de enfrentamento às situações estressógenas.
\end{abstract}

Palaurasdhave Psicossomática; Hipnose; Câncer de próstata.

\section{Hypnosis in oncological patients: a psychossomatic study on prostate cancer patients}

\begin{abstract}
This research aims at interpreting and understanding the impact of experiential experienced resignifications under the hypnotic state by each prostate cancer patient about of the self-perception of health, thrust in treatment and capability of prospecting the future. 12 patients were companied along 5 one-hour sessions of hypnotherapy weakly. The instruments consisted of individual interview, hypnotic interventions and interviews records. It was chosen the Thematic Analysis Technique to select the subjects to be analyzed. The speeches in initial interviews showed similarities about life experiences. The notable topics analyzed were: Feelings and impulses about the impact with the diagnosis, Meanings of cancer and thrust in cure, Self-perception about cancer improvement and Resumption of capacity of prospecting the future. Conclusion indicated that $100 \%$ of the followed patients mentioned felling themselves better about the health, thrust in cure, improvement in the humor and increases on the strategies with stressing situations.

Keguads Psychossomatic; Hypnosis; Prostate cancer.
\end{abstract}

\section{H ipnosis en pacientes oncológicos: un estudio psicosomático en pacientes con cáncer de próstata}

\begin{abstract}
Resumen
La presente investigación tiene como objetivo interpretar y comprender el impacto de las resignificaciones vivenciales experienciadas en estado hipnótico por pacientes con cáncer de próstata sobre la autopercepción de salud, creencia en el tratamiento y capacidad de prospectar el futuro. Fueron acompañados 12 sujetos durante 5 sesiones de 1 hora de hipnoterapia escalonadas semanalmente. Los instrumentos consistieron en entrevistas individuales, intervenciones hipnóticas y registros de las entrevistas. Fue escogida la Técnica de Análisis Temático para la selección de temas a seren analizados. Los discursos emergidos en las entrevistas iniciales presentaron semejanzas en lo que respecta a las vivencias coexistenciales y los tópicos notables analizados fueron: Sentimientos e impulsos al impacto del diagnóstico, Significado del cáncer y creencia en la cura, Autopercepción de la mejora del cáncer, Retomada de la capacidad de prospectar el futuro. La conclusión indicó que $100 \%$ de los pacientes acompañados refirieron mejora en la salud, certeza de cura, retomada del humor e incremento en las estrategias de enfrentamiento a las situaciones estresógenas.

Palabrasdave Psicosomática; Hipnosis; Cáncer de próstata.
\end{abstract}

Uma questão curiosa na história da hipnose é que, mesmo sem atender às exigências de cientificidade, ela sempre foi marcada pela eficiência terapêutica de suas abordagens, tendo a discussão sobre a hipnose sido inicialmente retomada, em termos clínicos, a partir da obra de Milton Erickson (Neubern, 2006). Um aspecto sobre o tema hipnose que, certamente, levanta questionamentos quanto a sua validade enquanto método científico é a ausência de um consenso quanto ao que seria e quais as suas técnicas e domínios. Assim sendo, no presente trabalho as ideias e concepções de Erickson nortearão as intervenções e conjecturas de objetivos.

De acordo com Erickson (2007), "a hipnose é fundamentalmente um método de comunicar ideias ao outro. Na hipnose, ao se colocar a pessoa em estado de transe, estabelece-se uma condição de predisposição às ideias, um estado de disposição para utilizar aprendizagens" (p. 19). "A hipnose não é um sono fisiológico determinado da consciência; é um estado psicológico determinado da consciência, que difere do estado comum da consciência" (Erickson, 2003, p. 53), visto ter havido um rebaixamento do estado de consciência: 0 transe.

Emst (2001) define a hipnoterapia como uma forma cognitiva de processamento de informação que se realiza a partir do rebaixamento da consciência com o objetivo de promover mudanças aparentemente involuntárias na percepção, humor, memória e fisiologia. 
Podemos, sucintamente, diterenciar hipnose clássica de hipnose Ericksoniana da seguinte maneira: na "hipnose clássica a indução de transe formal está associada às sugestões diretas" (Bauer, 2003, p. 64), enquanto a hipnose Ericksoniana consiste num "método criado por Erickson de se fazer um tipo exclusivo de transe para cada cliente, fazendo-o ficar ao molde de cada cliente" (Bauer, 2003, p. 240), sendo "a essência da hipnoterapia evocar respostas e potencialidades de dentro do paciente (Erickson \& Rossi, 2003, p. 40).

Uma vez que Erickson (2003) propõe uma hipnoterapia que coloca em foco a singularidade do sujeito e que "os novos conceitos de hipnose terapêutica enfatizam os processos psicobiológicos naturais de transdução de informação para acessar e facilitar a utilização dos próprios recursos interiores dos pacientes para a solução do problema" (Rossi, 2003, p. 300), a técnica da hipnose pode representar uma ferramenta coadjuvante importante no tratamento de pacientes com câncer de próstata.

Por outro lado, a progressão do câncer de próstata é explicada a partir do mau funcionamento da glândula prostática, ou seja, quando esta não detém 0 controle sobre a regulação do hormônio androgênico intraprostático; o que faz com que o câncer cresça, sendo regido a partir dos fatores hormonais de modo autônomo, explicam D enis, Gospodarowicz e Griffiths citados por Pollock e cols. (2006).

Considerando essas concepções, Bloch, Love, Macvean, D uchesne, Couper e Kissane (2007) referem que ao se dar o diagnóstico de câncer de próstata e de seus consequentes tipos de tratamentos, estamos colocando à disposição do paciente e de seus cônjuges questões existenciais concernentes a possíveis sequelas decorrentes de tais intervenções; 0 que implica a capacidade de enfrentamento e de adesão do paciente ao tratamento e o desenvolvimento de comorbidades de ordem psicológica ou psiquiátrica. Dessa forma, os autores propõem que as pesquisas sobre o tema atentem para compor estratégias de intervenção cujo objetivo sejam as necessidades psicológicas.

Portanto, podemos observar que há dois focos centrais quanto ao adoecimento nos pacientes que recebem 0 diagnóstico de câncer de próstata: 0 biomédico, inerente ao fato de ter câncer, e os decorrentes desse diagnóstico e das angústias existenciais que 0 mesmo deflagra. Esse todo psicossomático demanda uma estratégia de intervenção que implique a psique e o corpo de carne, como observou Spiegel (2007) ao afirmar haver a necessidade de se desenvolver uma ferramenta holística que permita acessar tanto a conexão mente-corpo quanto 0 contexto clínico.
Nas palavras de Mac Dougall (1983), o corpo, enquanto invólucro carnal que é, trata-se de um objeto para a psique, o que implica o fato de que sem corpo não haveria psique, e vice-versa. Desse modo, não há como se entender nem mesmo 0 afeto como um "acontecimento puramente psíquico ou puramente físico; a emoção é essencialmente psicossomática" (Mac Dougall, 2000, p. 107), posto que, segundo a autora, há uma relação entre os terrenos do soma e da psique, "propiciada pela dor, que surgindo em um destes terrenos, provoca inevitavelmente sofrimento ao outro; pelo menos enquanto o psicossoma funcionar como um todo saudável" (1983, p. 152-153), ou seja, integrado.

Ainda, segundo Rossi (2003), "qualquer intromissão ou mudança feita pelo mundo exterior pode desencadear uma doença cuja característica é a de ser um esforço para manter o equilíbrio homeostático" (p. 82). 0 autor explica essa dinâmica adaptativa considerando que o ser humano é dotado de um sistema detentor do "papel central de mediar a comunicação entre a fenomenologia da mente, tal como memória, aprendizagem, emoções, comportamento e suas manifestações psicossomáticas no corpo" (p. 146).

Logo, adotei uma postura terapêutica na qual considero a "psicossomática como uma ideologia sobre a saúde, 0 adoecer e sobre as práticas de saúde. Um campo de pesquisas sobre esses fatos e, ao mesmo tempo, uma prática..." (Mello Filho \& cols., 1992, p. 19), sendo "a psicossomática uma nova visão da patologia e da terapêutica, a qual foca a prática assistencial em se tratar doentes e não doenças", completa 0 autor (p. 19).

Mediante tais concepções, neste trabalho elegi a técnica da hipnose como ferramenta para promover a ressignificação das vivências relacionadas à concepção de saúde; instigar a ressignificação atribuída ao câncer de próstata e ao impacto desta na autopercepção de recuperação da saúde e da crença na cura; investigar como a hipnose contribuiu para 0 incremento da vontade de viver e, consequentemente, de projetar 0 futuro.

Pelo caráter subjetivo dessas vivências e autopercepções, utilizei 0 método qualitativo e a técnica de análise temática dos resultados como recursos científicos para a compreensão das propriedades benéficas da hipnose ante a dor, ansiedade, bem-estar, qualidade de vida, melhora do câncer, dentre outras.

\section{A mocodoga qualitativa}

Em termos gerais, Neubern (2009) salienta que os procedimentos metodológicos estatísticos e 
experimentais distanciam-se do contexto relacional em que os processos hipnóticos emergem, para se centrar apenas nas respostas isoladas dos indivíduos. Dessa forma, a pesquisa qualitativa estaria a oportunizar que as emoções quanto ao processo e tudo o que possa contribuir para constituir a subjetivação presente na hipnose seja assumido dentro de sua complexidade, que engloba a autopercepção quanto ao fenômeno hipnótico.

Turato (2003) ressalta como característica central da pesquisa qualitativa a atenção voltada para se investigar com os fenômenos são vivenciados e interpretados pelos sujeitos da pesquisa, sendo algumas peculiaridades inerentes ao método qualitativo: "1) a pesquisa é naturalística; 2) tem dados descritivos; 3) a preocupação é com o processo; 4) ela é indutiva e 5) a questão da significação é essencial" (Turato, 2003, p. 245). Assim sendo, como pondera o próprio autor, tem-se que "os sentidos e as significações dos fenômenos são 0 cerne para os pesquisadores qualitativistas, de modo que devemos procurar capturálos observando os sujeitos da pesquisa, bem como dar as interpretações" (p. 246).

Assim, a fim de atender às premissas científicas qualitativistas e dar suporte ao objetivo do presente trabalho, a amostra foi composta a partir do critério de saturação de dados, considerando, portanto, que "os sujeitos são incluídos e reunidos pelo critério da homogeneidade ampla; a amostra é fechada quando as respostas de novos informantes tornam-se expressamente repetitivas, na avaliação do pesquisador" (Turato, 2003, p. 366).

\section{A pesquisa}

Foram acompanhados pacientes com câncer de próstata que realizavam tratamento médico no Setor de Oncologia do Hospital de Força Aérea do Galeão HFAG. Estes realizaram tratamento hipnoterápico consistindo de cinco sessões, escalonadas semanalmente, com duração média de uma hora cada, tendo como critério de inclusão ser paciente do Setor de O ncologia do HFAG, diagnosticado com câncer de próstata, e não possuir diagnósticos psiquiátricos delineados nem fazer uso de substância psicoativa.

Apresento a seguir os participantes desta pesquisa (Tabela 1), com a finalidade de oportunizar ao leitor observar 0 critério de heterogeneidade ampla que norteia os dados amostrais. No entanto, observo que apesar desta característica heterogênea dos participantes, os dados obtidos e analisados foram homogêneos.

As entrevistas tiveram como norteadores dois roteiros de entrevista semidirigida (Quadros 1, e 2) para a coleta de dados, sem contudo limitar-se a estes; de modo a permitir que o fluxo fluísse naturalmente e que seu conteúdo pudesse ser abrangido em maior profundidade.

Tabela 1. Caracterização amostral dos pacientes participantes desta pesquisa

\begin{tabular}{|c|c|}
\hline Sujeito & Caracterização \\
\hline 1 & $\begin{array}{l}\text { J.C.S., } 53 \text { anos, casado, dois filhos, reservista, kardecista, pós-cirurgiado há } 7 \text { anos, cintilografia óssea sem } \\
\text { mestástases ósseas, biópsia: adenocarcinoma gleason } 7(3+4) \text {. }\end{array}$ \\
\hline 2 & $\begin{array}{l}\text { L.A.S., } 80 \text { anos, segundo casamento, um filho, pós-cirurgiado há } 9 \text { anos, cintilografia óssea sem alterações, } \\
\text { biópsia: adenocarcinoma gleason } 2(1+1) \text {. }\end{array}$ \\
\hline 3 & $\begin{array}{l}\text { N.C.S., } 71 \text { anos, casado, dois filhos, reservista, evangélico, pós-cirurgiado há } 7 \text { anos, cintilografia óssea sem } \\
\text { mestástases ósseas, biópsia: adenocarcinoma gleason } 7(3+4) \text {. }\end{array}$ \\
\hline 4 & $\begin{array}{l}\text { J.S., } 66 \text { anos, casado, dois filhos, policial civil aposentado e reformado, kardecista, pós-cirurgiado há } 5 \text { anos, } \\
\text { cintilografia óssea sem mestástases ósseas, biópsia: adenocarcinoma gleason } 6(3+3) \text {. }\end{array}$ \\
\hline 5 & $\begin{array}{l}\text { A.S.S., } 69 \text { anos, casado, dois filhos, católico, sem intervenção cirúrgicas, cintilografia óssea indicando ósseos } \\
\text { blásticos secundários, biópsia: ainda aguardando o resultado. }\end{array}$ \\
\hline 6 & $\begin{array}{l}\text { I.O.B., } 59 \text { anos, segundo casamento, dois filhos, enfermeiro, católico praticante, sem antecedentes cirúrgicos, } \\
\text { cintilografia óssea indicando aumento da atividade osteogênica, biópsia: adenocarcinoma Gleason } 8(4+4) \text {. }\end{array}$ \\
\hline 7 & $\begin{array}{l}\text { A.S.B., } 60 \text { anos, casado, três filhos, empresário, católico, pós-cirurgiado há } 1 \text { ano, cintilografia óssea sem } \\
\text { metástases, biópsia: adenocarcinoma gleason } 6(3+3) \text {. }\end{array}$ \\
\hline 8 & $\begin{array}{l}\text { L.G.T., } 59 \text { anos, segundo casamento, dois filhos, reservista, católico, sem intervenção cirúrgica, cintilografia óssea } \\
\text { apresentando osteopenia e osteoporose, biópsia: adenocarcinoma gleason } 8(4+4) \text {. }\end{array}$ \\
\hline 9 & $\begin{array}{l}\text { J.T.C., } 84 \text { anos, casado, } 2 \text { filhos, reservista, católico, sem intervenção cirúrgica, cintilografia óssea sem metástases, } \\
\text { biópsia adenocarcinoma gleason } 6(3+3) \text {. }\end{array}$ \\
\hline 10 & $\begin{array}{l}\text { U.M., } 97 \text { anos, casado, } 3 \text { filhos, reservista, católico, sem intervenção cirúrgica, cintilografia óssea sem metástases, } \\
\text { biópsia: adenocarcinoma gleason } 4(2+2) \text {. }\end{array}$ \\
\hline 11 & $\begin{array}{l}\text { A.C., } 69 \text { anos, casado, } 2 \text { filhos, católico, pós-cirurgiado há } 9 \text { anos, cintilografia óssea sugestiva de alterações } \\
\text { degenerativas, biópsia: adenocarcinoma gleason } 6(3+3) \text {. }\end{array}$ \\
\hline 12 & $\begin{array}{l}\text { W.A., } 73 \text { anos, casado, } 3 \text { filhos, católico, sem intervenção cirúrgica, cintilografia óssea sem alterações, biópsia: } \\
\text { adenocarcinoma gleason } 6(3+3) \text {. }\end{array}$ \\
\hline
\end{tabular}


Quadro 1. Roteiro de entrevista realizada com cada paciente antes do início do tratamento hipnoterápico

Quando o senhor recebeu o diagnóstico?

Como recebeu a notícia? Quais foram os seus primeiros pensamentos?

Após a notícia de que tinha câncer, realizou cirurgia? Quais foram os prós da cirurgia? Quais foram os contra? 0 senhor diria que a cirurgia correspondeu às suas expectativas?

Quais eram as suas expectativas?

Continua a sua rotina como antes da intervenção e do diagnóstico? O que mudou?

Na ocasião do recebimento do diagnóstico quais imagens te vieram à mente?

Como visualiza as células de seu câncer atualmente? O que significa ter câncer para você?

Já tinha imaginado esta possibilidade em algum momento de sua vida? Quando? Por quê? Como se sentiu?

Conhece alguém que teve câncer? Como foi a evolução do quadro clínico desta pessoa?

Você acha que pode ajudar a se curar mais rápido? Como? Por quê?

Qual a sua lembrança mais agradável?

Quadro 2. Roteiro de entrevista realizada com cada paciente antes de cada sessão de hipnoterapia

Quais as suas expectativas para a sessão de hoje?

Quais são os seus projetos para a sua vida hoje?

Como o senhor descreveria as suas células de câncer no momento?

Qual o significado de ter câncer para o senhor?

Como tem sido a sua rotina?

Tomando por base os conteúdos dos discursos emergidos nas entrevistas quanto à visualização que cada paciente fazia de suas células oncológicas e do significado de ter câncer para cada um, e associando essas percepções às expectativas individuais foi conformada cada intervenção hipnótica. A segunda entrevista tinha como função nortear as estratégias de aprofundamento do transe em cada sessão, a fim de facilitar a ressignificação das vivências.

\section{Instrumeto}

Concisamente pode-se compreender que "0 processo da psicoterapia Ericksoniana tem basicamente três passos, que são: preparação, intervenção principal e acompanhamento. Devendo ser na primeira destas etapas que o terapeuta tem que fazer mais operações, ou seja, na hora de preparar" (Robles, 2005, p. 191).

Estão a seguir as estratégias de indução e aprofundamento do transe hipnótico, observando que durante a fase de aprofundamento, sugestões hipnóticas são feitas. Ressalto ainda, a utilização do treinamento Autógeno de Schultz no processo de indução. Este consiste, segundo Masson (1986), em conduzir o paciente a uma concentração descontrativa, sucessivamente, nos músculos, sistema vascular, coração, respiração, órgãos abdominais e cabeça.

\section{Momento: Preparação/ Indução}

Senteseeproare uma posição omais confatánd posśvi... Perdba sau corpa.. Rdaxe.. Sdte os bracos libere as pemas Rdaxe o pescosa.. Endha letamente os pulmões dear... evja uma luz branca passando por suas nanimas e entrandb em sal corpa.. dhegandb atéos pulmões.. V gia saus pulmões inflarem.. Sqpre o ar pda boca. Lentamente V gja uma fumainha sainda.. Levando embara qualquer tensãa desconforto, preaupaçãa.. Sinta opeso do sal corpo sdbrea pdtrona... Sinta ocansaco do sal corpa.. Rdaxe Sinta-selee Endha maisuma vez os pulmóes dear... V agarosamente.. Sdte, mais uma vez, o ar pala boca. Peceba opeso desar compa.. ocansaca.. opesoleve de sal compa.. Sinta sal conpo ficando leve leve leve.. flutuanda.. E nesta lezza voêsó avea minha voz, eosamda música... calma eagradáve... Segura. Enhra mais uma vez os pulmões de ar... Libere o pensamenta.. Pensamento é gaivda! Passa. Vocêfica. V oêé Nada pode after a sua alegia na vida.. parquepensamento égaivda.. passa... O moimento éa gandeconstante.. Seu coração bateno pefeito nitmo ircadiana Sua pressão arteial se mantém na justa meelida a fim de que você possa descansar. Descanse Sua respiração abodominal está cada vez mais plena. Sinta o sangre dentro de sal comp.. O calor vital dentro de voce... A saúde $\mathrm{O}$ sangue araulandb e levandb calor, enegia, vida, saúdeehammia desdea pantinha desau deefão atéa ponta dofio decabdo mais distante.. V gja a unha de sau decão crar. V oê sentese ainda mais ralaxadb e comuma agadáved vontadedeadomeer para uma nitedesano acondhegante e revigarante Uma nite ma qual você podká sonhar etomar realidadesaus desgos mais profundbs.. Permitase

$2^{\underline{0}}$ Momento: Aprofundamento do Transe

V đê pode domir... É isso o que vơ̂ quer, não ê Duma pesada.. profundamente Mas a todb o tempo continuará satandb a minha voz e o som da mísica ao funda.. segura.. em hammia.. Duma!... Duma profundamente... Descanse.. Duma. Agra vocêse encantra 
em um bdo campa V jal Apreie.. Sinta a brisa fresca da manhã... Sinta o sd mmo do amanhexe..., com que te abraçanda.. Trazendb uma agadáved sensação de carinho, petenimento segurança... Pise o avalho fresco do amanheer. O cál etá azul... Neste enome campo há mitas árvares.. árvores altas, árvores baixas, árvores comfolhas mito vedes árvores comfolhas mais secas.. árvores comfdhas amardadas.. mas cada uma guarda a sua bdeza. Observel Peceba... Ouga o sam dos pássaros.. Neste enome campo vocêtambém podever uma dareira.. uma dareira rockeada de flores raras e mito belas.. Sinta seu pefume Assim é fïta a vida. Feita de estaçáes demmentos.. Há momentos para plantar. Momentos para colher... Momentos de epera. Mas cada um tema sua bdeza... Sinta a tranquilidade e a hammia. E voê dome cada vez mais pesado mais profunda..; não é Indb cada vez mais de encontro aos saus desgos mais íntimos, mais inconsientes.. Nette campo voê ave um sam de ágra... caminhe.. caminhe em direģão ao sam deágra... Pode ser um nio ummar, umniacho uma fonte.. Vá em diresãa ao som agadáve e calmante da ágra. Lá voê encontra uma escada; uma scada em espiral que desce uma escada em espiral cm degraus demámme branco, éuma escada arta... emespiral... quedesce... Sãoapenas inco deyraus demámmebranco, mito branca.. É uma ecada fáil de descer...emespiral... E a cada deyzau quevoêdesce, voêdomemais profundo, mais pesada.. sel etágio desonho fica cada vez mais profundbeplena.. Mas vocêsemprecontinuará auindb a minha voz, esóa minha voz. Desca o primiro degrau da escada em espiral que desce e o deyrau demámme branco seacende cama luz laranja... Sinta a vitalidade desta car... de um brilho jamais visto par vôe... Demrese quanto quiser nete degrau.. e rguvenesca. Desca agra o deyau denúmero dis da scada emespiral quedesce.. É uma escada arta.. Pemita-se.. A citedebomgadb oque as sensaçóes e os sanhos te trazem.. V cê pode se assim 0 desgar. São apenas inco deeyaus.. e quandb você dhegar ao deyau de númeo anco voê stará sonhandb profundamente coma relização de seus descos mais profundos einconsientes de pez, hammia, alegia, saúde, juxentude, tranquilidade.. Mas apenas quandb eu falar o número anca. Este deyrau de número dis se acende com a luz amarda. É com se um holofte te iluminasse.. Desca o texciro deyau de námme mito branca.., da escada em espiral que desce.. Este se ilumina coma luz azul... o azul da pez, da confiança, da ceteza da realizaçãa.. Umazul jamaisvistoigual... Apreie... Sinta.. Descanse.. Duma.. Desca agra o deyau denúmero quatro, sabendb que tão logo voêe pisar o deyau de número ánco vocêse encontrará ditadb confortáved eacondhegantemente numa praia, ou sobre uma nuvem.. macia.. Mas apenas quandb eu falar o númeo ánca $\mathrm{O}$ degrau denúmero quatrose acende eseilumina coma sua cor prefeida, quese espalha por todb o sel ser... E voêsesentelive... com seflutuasse sobre uma nuxem.. emuma nuvemmitomada... segura, elá doalto voê pode apreiar a tera, a sua vida... e voê dome ainda mais..descansa... V cêa agra dha para baixo para oúltimo deyau da escada demámme branco da escada emespiral que desce.. Piseo degrau denúmerocinco.

É importante ressaltar que as estratégias de aprofundamento de transe sofreram variações de acordo com as lembranças e relativas imagens relatadas pelos pacientes durante as entrevistas, bem como foram configuradas respeitando 0 estado de relaxamento atingido a partir da indução, o nível de tensão apresentado em cada sessão e a maior facilidade ou não de se entregar ao processo hipnoterapêutico.

As entrevistas form registradas, e as falas transcritas encontram-se fielmente reproduzidas.

\section{Resultados e análise dos dados}

Os discursos emergidos nas entrevistas iniciais apresentaram semelhanças no que concerne às vivências coexistenciais, como se pode observar nos trechos seguintes. Associações do câncer com sofrimento, preconceito, covardia, impotência, decreto de morte, aprisionamento, dentre outras emoções, estiveram presentes em todos os relatos, assim como a dificuldade em contar 0 diagnóstico para seus familiares. As falas a seguir ilustram essas vivências.

"Quandofala decâncer sólembra sofimenta.. Há pesscas que quandb falam de voê até sentem nijo” (J.C.S.). “V gio o câner combalgoquelimita oindiv́dua Podal"

"Acitam entre aspas Parque ninguém acita um problemas desses"... A minha milher fai minha maior preaupação parque da achava que el não tinha câncer" (A.S.S.) referindo-se sobre como foi difícil lidar com a situação de contar para seus familiares que tinha recebido o diagnóstico de portador de câncer de próstata).

"Esta doença écovarde, sinistra" (W.A.). Eu não penso nocâner. Nãogostonemquecomentem Peguntamsdbreatras cisas caração elema da pema..."

"Na hara a gente só pensa no pior. Câmer!! (N.C.S.). "Os méelicos queam mas não garantem.. O pensamento só é quedheguraofim".

“O impacto do dagó́tico fá tenvid...” (A.C.). "Ninguémgosta delembrar... Chorava no mitrôigual ciança.. Para sair sozinhotinha difiaildade".

"Quandb o mélico disse encarè com naturalidade.. mas quandb dhegui para a famlia... Poxa! Muito grave a minha situaçãa Quase que el fiz um testamento Fo com uma sentença demate' (I.O .B.).

"Não meabale mitoparquejá conivo camo (cânces) da minha mãè" (A.S.B.). "Quandb fui pegar or resltado db exame pense: eu posso estar... [comcâncer]. Então meprepare para o pior. Mas numa queendb que aconterse.. Mas se acnterese euia supear... Mastorcendb para quenão estivesse".

"Minha única preoupacão ea tirar o tumor de detro de mim.. Ficarlive.." (J.S.). 
As vivências existenciais experimentadas por esses pacientes implicavam um medo intenso acompanhado de forte sentimento de desamparo. Um medo muito mais do desconhecido do que das reais possibilidades de cura, tratamentos e efeitos colaterais e sequelas decorrentes de seu diagnóstico. Observou-se uma grande concepção mítica do câncer ainda nos dias atuais, pois apesar da coragem de proferir a palavra câncer, todos os pacientes relataram algum tipo de preconceito seu, de seus familiares ou de seus amigos no que diz respeito ao que era na realidade seu estágio de câncer e a respectiva gravidade de seu quadro. Esses preconceitos foram muito responsáveis pela dificuldade de aceitação, por parte dos entes queridos, do diagnóstico de câncer. Consequentemente, dificultaram ao paciente que este pudesse compartilhar seus temores e angústias. Fato que contribuiu significativamente para o sentimento de solidão e desamparo experimentado pelos portadores de câncer.

Outro aspecto importante foram as diversas comorbidades apresentadas por todos os pacientes. Essas funcionaram como válvula de escape para 0 medo, a ansiedade, a preocupação e a tensão com 0 câncer na medida em que serviram como doenças encobridoras ao diagnóstico principal de câncer de próstata, levando os pacientes a diversas clínicas, que não a oncológica, e a variados profissionais, que não 0 oncologista.

As variáveis estado civil e religião mostraram-se relevantes na medida em que, a princípio, ambas poderiam ser ingenuamente compreendidas como elementos facilitadores para lidar com o diagnóstico, com o tratamento, suas implicações e possíveis reações adversas. Entretanto, aspectos relacionados ao estado civil revelaram não serem indicadores de menor sentimento de desamparo. Isso porque, embora todos os pacientes entrevistados fossem casados, pode-se observar que o cônjuge não foi alguém com quem pudessem compartilhar as angústias diante do diagnóstico e implicações ante 0 tratamento. Esse estado civil foi, sobretudo, algo que deixou os pacientes mais angustiados e preocupados, pois temiam que seus cônjuges não conseguissem lidar com aspectos burocráticos da vida, tais como bens, contas a pagar etc. Ainda, o fato de serem casados os forçou a analisar a possibilidade de morte iminente a fim de que pudessem tomar as atitudes cabíveis de forma a não deixar seus cônjuges desamparados. Preocupações semelhantes foram associadas aos filhos.

Por seu turno, a religião também não apresentou caráter confortador. $\mathrm{O}$ medo, a angústia e o desamparo suplantaram todos os níveis de fé, inclusive a de um pastor protestante. Este, após o diagnóstico optou por se afastar da função. Em vários casos, os pacientes referiram que em outras circunstâncias não teriam pensado na hipnose.

Este levantamento propiciou, com base na Técnica de Análise de Conteúdo (Bardin, 1979), a emersão de tópicos notáveis, cuja presença ou frequência de aparição na comunicação podiam significar algo sobre o objetivo escolhido para esta pesquisa, e que detinham propriedades suficientes para se tornarem "categorias" ou "temas" e, por essa razão, foram eleitos para aprofundamento.

As categorias que mereceram destaque de análise de conteúdo em virtude da grande recorrência e angústia que despertavam nos pacientes foram as seguintes: 1) Sentimentos e impulsos ao impacto do diagnóstico; 2) Significado do câncer e crença na cura; 3) A auto-percepção da melhora do câncer; 4) Retomada da capacidade de prospectar o futuro.

\section{Sentimentos eimpulsos aoimpactodbdiagnótico}

Bloch e cols. (2007) pontuam que a adaptação psicológica ao diagnóstico de câncer de próstata tratase de algo complexo, pela trajetória em potencial deflagrada desde 0 momento do diagnóstico, considerando desde o seu impacto imediato até a fase de cuidados paliativos, a qual é acompanhada por várias questões existenciais, conforme indicam as falas a seguir:

"Foi umsusto mito gande A primira cisa queeu fiz fai parar, sentar eficar pensanda.." (J.S.)

"Na hora a gentesó pensa nopiar. câncer! O pensamento só é que heegu ao fim.. Tenho conheidos que venderam tudb quandbsauberamdodiagnóstiơ" (N.C.S.)

"Pense logoemdexar tuda.. Passe camo, casa, tdefone.. tudb para minha esposa, parquenão tenhoseguro devida... Não querodar trabalho para minha esposa." (L.A.S.)

Sendo assim, atentei para o estado de angústia e de desesperança verbalizado ou não pelo paciente no momento inicial ao tratamento hipnoterápico. Esse cuidado se justificou porque quanto mais intensa a carga afetiva que uma situação desperta, mais conflitos, dúvidas e inseguranças o indivíduo tende a apresentar, bem como maior será a sua descrença na possibilidade de ser ajudado e, portanto, retomar a cura e a saúde.

Nos relatos colhidos e analisados, a palavra câncer possuía significado de morte iminente. Compreender 0 câncer como sentença de morte apresentou repercussões nocivas aos pacientes, dificultando, num primeiro momento, a elaboração do diagnóstico e a verbalização clara de suas angústias quanto ao diagnóstico e às limitações e efeitos colaterais dos tratamentos. Os pacientes precisavam manter um controle rígido de seus egos, a fim de evitar uma psicossomatização que repercutisse em sua capacidade de racionalizar a situação, e então tivessem 
forças para superar o trauma. Dessa forma, uma intervenção psicológica com roupagem hipnótica foi algo muito bem recebido por todos, uma vez que não os deixava em descoberto com eles mesmos num momento de intenso conflito egoico. Ao mesmo tempo, oferecia-lhes a oportunidade de dividir suas angústias e posteriormente escutá-las de si próprios e permitir que as mesmas pudessem ser vivenciadas e resignificadas.

“Quandb o médico falau do nódulo, eu pense: eu posso estar... entãoeu meprepare para opior...

"É uma sentença. Eu não entendi por que al etava otempotabtãotranquila" (A.S.B.)

“... Impotênia emtodos os sentidbs E agara? Comoéque vai sæ? Eu mesenti aarada Comæei a pensar emmate.. Não pense emvida" (I.O.B.)

“Dr.: Pedil, né?!" (J.S.)

As queixas relativas a alterações de humor, aparecimento de dores diversas, edemas e outras, após 0 diagnóstico, também foram recorrentes. Todas desempenhavam função de sintoma encobridor de uma angústia ou conflito inominável inerente àquela conjuntura e/ ou atuavam como válvula de descarga psíquica para as inquietações existenciais que 0 diagnóstico de câncer deflagrou, as quais representaram estratégia inconsciente crucial no restabelecimento da saúde, provavelmente por duas razões: seus sintomas despertaram a ajuda familiar e a busca pelo auxílio médico, ao mesmo tempo em que espiaram uma parte da carga aflitiva não-elaborável naquele momento de vivência de sentença de morte.

Ainda, a análise qualitativa dos conteúdos das falas dos pacientes indicou exatamente o que Mac Dougall (2000) afirma: que aqueles pacientes que "foram capazes de somatizar suas dores mentais nos momentos em que suas defesas habituais falharam diante do sofrimento psíquico" (p. 66) foram aqueles cujos melhores resultados de cura se sucederam.

Enquanto psicoterapeuta, "tudo o que se teve de fazer foi reconhecer as deixas e a variedade da conduta humana, das respostas corporais, das respostas neurológicas e depois se dar conta de que para todas estas respostas somáticas existe um componente psicológico de algum tipo" (Erickson, 2007, p. 41), a partir do que foi composta a hipnoterapia sob medida.

\section{Significadbdbcâner ecrença na ara}

O utro aspecto relevante remete às autopercepções dos pacientes no momento das entrevistas que diz respeito à imagem negativa e pessimista que os pacientes tinham sobre as características de malignidade e desenvolvimento das células do câncer, como se pode constatar: (J.S.)

"São como uma madkira quandb da etá apodreenda" (A.S.S.)

"Uma ciatura capenga.. fica mio manco coxa.."

"É tipo assim um caroso que forma.. as celulas ficam motas.. dali cia uma massa. Para mim da émaligna. Fica dentrodbarganismoenãoservepara nada..." (N.C.S.)

No entanto, suas percepções encerravam um caráter ainda não elaborado da concepção da célula oncológica como algo inferior, de menor qualidade e poder; embora nenhum dos pacientes apresentasse consciência disso.

Porém, apesar de todos os pacientes entrevistados descreverem essas células como debilitadas, todos demonstravam em seus discursos a certeza de que era como se as mesmas fossem portadoras de livre-arbítrio, maior força e poder que as demais células de todo 0 corpo, bem como de poder de decisão diante da eficácia ou não do tratamento medicamentoso. Essa crença exacerbada e irracional na malignidade das células repercutia em sua qualidade de vida, dificultava a crença na cura e nos tratamentos realizados, bem como na projeção de um futuro longínquo e agradável.

Entretanto, o decorrer das sessões de hipnose oportunizou a emersão de um novo rumo para as questões de crença na cura, percepção das células de câncer e capacidade de projetar o futuro. Isso foi sendo possível porque, através das vivências hipnóticas, as quais instigavam a ressignificação dessas questões, 0 significado do câncer e, consequentemente, 0 do que é ter câncer, foi se modificando. E o diagnóstico, 0 grande vilão, passou a produzir uma dinâmica psíquica com base em conteúdos traumáticos verbalizáveis, portanto, elaboráveis.

Assim sendo, coube-me oportunizar um estado de transe o qual sintetizasse visualmente, em forma de vivências reorganizadoras, a regulação dos estados físicos neuroendócrinos, a transdução de informações celulares e, consequentemente, uma melhora no humor geral. Ao mesmo tempo, era de suma importância que logo num primeiro momento as experiências sensoriais a serem reaprendidas, em forma de sentimentos, fossem vivenciadas sob hipnose de forma agradável emocionalmente e, consequentemente, integradas ao todo psicossomático. Essas vivências repercutiriam nas aprendizagens dependentes de etadb (Rossi, 2003), ou seja, nos estados psicoendocrinoneuroimunológicos, os quais refletem na saúde psique-soma.

No que concerne ao humor, a primeira mudança constatada foi a do caráter pessimista do pensamento quanto à malignidade e autonomia das células oncológicas, refletindo num humor mais autoconfiante e oportunizando a elaboração de novos conceitos e compreensões sobre as mesmas. 
"Ela [a clula ondógica] éigual às atras db arganism, masmaisfraquinha... Mais ddbilitada." (J.C.S.)

"É com se eu não tivesse nada. Eu tô engurdando de nova.. nãotá meatrapalhandoemnada. Eu sei queoproblema existe mos exams, mas fisicamente é como se au não tivese" (I.O.B.).

\section{Autopercexãada milhora docâner}

Robles (2005) pondera que, para que um tratamento hipnoterápico atinja seu objetivo, é necessário que este possua uma meta; apenas dessa maneira saberemos para onde devemos levar a psicoterapia. Portanto, faz-se necessária a investigação dos significados, das angústias e das expectativas de cada paciente quanto a sua doença e sua vida, durante todo o processo do tratamento hipnoterápico.

Uma vez que "a hipnose faz com que o paciente tenha à sua disposição os seus próprios potenciais para a auto-ajuda" (Zeig, 2003, p. 35), pude constatar que, conforme se revive hipnoticamente 0 episódio traumático do diagnóstico e dos possíveis prognósticos que 0 mesmo pode representar, oportuniza-se que 0 paciente ressignifique essa vivência de uma maneira mais aceitável para si próprio, com uma roupagem mais amena, a qual permita a elaboração do trauma.

Foi, de fato, o que ocorreu, como indicam as seguintes percepções:

"A minha expetativa éque eu venha a reuperar toda a minha saúde, questá abalada." (A.S.S.)

"Essa calu [db câncer] é de accrdb com aquilo que a gentesente, comoestadbdehumr". (I.O.B.)

"Comp eu 'tố ciandb alguma ceisa, eu tenho queajudar também" (A.S.B.)

"A minha tranquilidade aumentau.. A gete fica mais segura" (N.C.S.)

Ao permitir a elaboração do trauma, automaticamente 0 indivíduo pode prescindir do recurso de gerar atos-sintoma, sintomas encobridores, somatizações, transtornos de humor e de ansiedade; 0 que por outro lado possibilita que 0 indivíduo encare com maior serenidade e destituído de pré-conceitos socialmente compartilháveis às expectativas diante das oportunidades e possibilidades do futuro, apesar de ter o diagnóstico de câncer.

\section{Retamada da capacidadedeprospetar ofuturo}

Cada nova autopercepção funcionou para mim, enquanto psicoterapeuta, como uma dica de que passei a ter a meu dispor mais uma ferramenta terapêutica, posto que "qualquer comportamento, qualquer manifestação... podem ser utilizados como ferramenta terapêutica" (Zeig, 2003, p. 85).

Isso porque, se relembrarmos que os problemas psicossomáticos "são disfunções da comunicação mente-corpo num âmbito virtual” (Rossi, 2003, p. 91), uma vez havendo a sincronia mente-corpo, os pacientes readquiririam a capacidade de gerenciar e planejar novamente suas vidas. Assim, ressignificando a autopercepção da doença, do adoecimento e da saúde fez-se possível a aquisição de um estado psicossomático apto a elaborar as implicações decorrentes do diagnóstico e dos tratamentos, assim como uma diminuição da dor inconsciente ante essas questões.

Estando esta sincronia estabelecida, as prospecções sobre 0 amanhã retornaram e os pacientes começaram a apresentar projetos de retornar ao trabalho, de viajar, de comprar a tão esperada casa de praia da aposentadoria, ou um carro novo... A vida após o câncer passou a existir, ou seja, a crença de que o câncer era passageiro, cambiável e destrutível.

\section{Considerações finais}

O tratamento hipnoterápico desencadeou, com 0 transcorrer das sessões, uma reaproximação de cada indivíduo consigo mesmo, e uma decorrente compreensão de que seu estado atual de saúde era passageiro e cambiável. Estes, gradativamente se apropriaram do lugar de "ser uma personalidade total recuperando-se" (Erickson, 2007, p. 55), para o qual foram convocados a participar desde 0 início das sessões de hipnoterapia, ou seja, participavam ativamente de um processo de recuperação de sua saúde.

Certamente que "a experiência de reassociar e reorganizar sua própria experiência de vida foi o que pôde resultar em uma cura" (Rossi, 2003, p. 99), uma vez que a autopercepção de melhora pareceu estar diretamente relacionada ao aumento da capacidade dos pacientes de voltarem a ocupar a posição de agentes centrais de suas vidas.

Mediante essa constatação, foi possível observar que a noção eminentemente humana de qualidade de vida que, segundo Minayo, Hartz e Buss (2000), tem sido aproximada ao grau de satisfação encontrado na vida familiar, amorosa, social e ambiental e à própria estética da existência, tomou conta desses pacientes, e se encontrava refletida de uma maneira muito intensa em seus comportamentos e discursos. De modo que estes voltaram a acreditar na vida, na recuperação da saúde, no relacionamento conjugal e em si próprios enquanto seus maiores e melhores aliados.

A hipnoterapia sob medida Ericksoniana apresentou-se como estratégia muito relevante no sentido de auxiliar e oportunizar a cada paciente se perguntar e encontrar em seu inconsciente uma maneira de lidar e resolver seu conflito. Portanto, um 
trabalho interno que aproxime os desejos mais inconscientes e profundos pode trazer diversos ganhos para os pacientes, dentre eles a melhora do humor, a crença na cura e a melhor adesão ao tratamento, a melhora do câncer e a retomada da vontade de viver.

Os resultados obtidos por meio deste estudo indicam que a hipnose pode ser um importante aliado no tratamento das doenças autoimunes, auxiliando no restabelecimento do equilíbrio psicossomático e na ressignificação das experiências e significados subjacentes ao preconcebido sobre cada doença, adoecer, comorbidades, implicações e efeitos colaterais psicossomáticos inerentes.

Além disso, a capacidade de transdução celular em estado hipnótico guarda a possibilidade de associar, mediante a contiguidade entre vivências agradáveis ao paciente e sugestionamento de apropriação celular de funções, 0 restabelecimento de habilidades orgânicas perdidas. No entanto, há a necessidade de estudos sistematizados sobre 0 assunto.

Portanto, os estudos futuros devem atentar para ampliar o tamanho da amostra, delimitar o intervalo de idade dos participantes, o gênero, 0 tipo de câncer e 0 estadiamento do mesmo, o tratamento a que foi submetido, e a mensuração da suscetibilidade hipnótica. $\mathrm{O}$ atendimento dessas variáveis implica que 0 pesquisador seja acolhido em local com quantitativo de pacientes e staff engajados na referida pesquisa, assim como seja detentor de financiamento para a realização de exames comparativos entre os quadros inicial e final.

\section{Referências}

Bardin, L. (1979). Análise de contérdb Lisboa: Edições 70.

Bauer, S. (2003). Hipnderapia Eridksoniama passo a passa Campinas: Livro Pleno.

Bloch, S., Love, A., Macvean, M., Duchesne, G., Couper, J., \& Kissane, D. (2007). Psychological adjustment of men with prostate cancer: a review of the literature. Biqpsychosocial Mediane 1(2). [O nline]. doi: 10.1186/1751-0759-1-2. Recuperado: 14 dezembro 2009. Disponível: http:/ / www.ncbi.nlm.nih.gov/ pmc/ articles/ PMC 1805773/ ?log\% $24=$ activity.

Ernst, E. (2001). Complementary therapies in palliative cancer care. American Canrer Socidy, 91(11), 21812185.
Erickson, M. (2003). Hipnose mécica e obntdớica. Campinas: Livro Pleno.

Erickson, M. (2007). Seminarios de introdurción a la hipnosis México: Alom Editores.

Erickson, M., \& Rossi, E. (2003). O homem de fexerera Campinas: Livro Pleno.

Mac Dougall, J. (1983). Em defea de uma cata anomalidade Porto Alegre: Artes Médicas.

Mac D ougall, J. (2000). Tetros do Corpa São Paulo: Martins Fontes.

Masson, S. (1986). Osrdaxamentos São Paulo: Manole.

Mello Filho, J., \& cols. (1992). Psicossomática hije Porto Alegre: ArtMed.

Minayo, M. C. S., Hartz, Z. M. A., \& Buss, P. M. (2000). Qualidade de vida e saúde: um debate necessário. Ciênaia \& SaúdeCdeliva, 5(1), 7-18.

Neubern, M. S. (2006). Hipnose e psicologia clínica: retomando a história não contada. Psicoga: ReflexãoeCńtica, 19(3), 346-354.

Neubern, M. S. (2009). Hipnose e dor: proposta de metodologia clínica e qualitativa de estudo. Psico USF, 14(2), 201-210.

Pollock, R. E., \& cols. (2006). Manual deonadoga dínica da UICC. São Paulo: Wiley Publishers.

Robles, T. (2005). Terapia fëta sdb medida Belo Horizonte, MG : Diamante.

Rossi, E. L. (2003). A psicdidoga da arra metecomp Campinas, SP: Livro Pleno.

Spiegel, H. (2007). The neural trance: a new look at hypnosis. Intemational Jaumal of Clinical and Expeimental Hyposis, 55(4), 387-410.

Turato, E. R. (2003). Tratado da mododogia da pesquisa dínicoqualitativa. Petrópolis, RJ: Vozes.

Zeig, J. K. (2003). Vivenaando Eridkson Campinas, SP: Livro Pleno.
Reedidoem10/ 08/ 2011

Reformuladoem05/ 03/ 2012

Aprovadoem06/ 03/ 2012 
Sobre a autora:

Licia Ferreira Caire é mestre em Psicologia Clínica: núcleo de psicologia hospitalar e psicossomática pela PUC-SP. Pós-graduada em Psicologia Médica e Psicossomática. Psicóloga Clínica e Pedagoga. Hipnóloga Clínica e Hipnoterapeuta. Acupunturista Auricular Clínica. Professora de cursos de graduação e pós-graduação.

Contato com a autora:

Rua Leo de Morais, 231 - apto: 51B, CEP: 04165-150. São Paulo.

Email: l.caire@ live.com 